\title{
Fine-Tuning Dye Adsorption Capacity of UiO-66 by Mixed-Ligand Approach
}

\author{
Chompoonoot Nanthamathee \\ Walailak University \\ Chantamalinee Chantarangkul \\ Walailak University \\ Chanida Jakkrawhad \\ Walailak University \\ Apirak Payaka \\ Walailak University \\ Pongsathorn Dechatiwongse ( $\square$ Pongsathorn.Dechatiwongse@gmail.com ) \\ Walailak University
}

\section{Research Article}

Keywords: Mixed-ligand approach, metal-organic frameworks, indigo carmine, Ui0-66, adsorption capacity

Posted Date: May 7th, 2021

DOI: https://doi.org/10.21203/rs.3.rs-490186/v1

License: (1) This work is licensed under a Creative Commons Attribution 4.0 International License. Read Full License

Version of Record: A version of this preprint was published at Heliyon on February 1st, 2022. See the published version at https://doi.org/10.1016/j.heliyon.2022.e08961. 


\section{Abstract}

Mixed ligand synthetic approach offers an alternative to engineer a specific character in metal-organic framework (MOFs) materials. Herein, we synthesized and characterized a well-known prototype zirconium based-MOF, so called UiO-66 and its mixed ligand derivatives UiO-66xATA, where $\mathrm{x}$ is mole fraction $(0.5,0.75$ and 1.0$)$ and ATA is 2-animoterephthalate. The aim of the study is to observe whether the dye adsorption capacity can be tuned/enhanced by the ATA ligand substitution into the framework. We found that, at room temperature, UiO-660.75ATA shows the highest adsorption capacity toward various dye solution including methylene blue (MB), indigo carmine (IC) and congo red (CR). The optimum adsorption conditions in all four materials were found to be in a common trend where their adsorption capacities can be increased with decreasing pH and adsorbent dose, increasing of IC concentration, contact time and temperature. Pseudo-second order kinetics model fits best with their adsorption data, where UiO-66-ATA has the fastest rate of adsorption. Langmuir and Freundlich isotherms were found to best describe adsorption behaviour in ATA-containing UiO-66 and UiO-66 respectively, where adsorption processes were found to be physisorption. Confirming by thermodynamic studies, the adsorption in all four materials occurred spontaneously, driven by entropy. Computational studies showed ligand to metal charge transfer where the distribution of electron densities was varied with the amount of functionalized ligand. Adsorption mechanism is proposed as a synergistic interplay between electrostatic interaction and hydrogen bonding. The findings in this work broaden potential strategy to fine-tune the dye adsorption capacity in MOF materials.

\section{Introduction}

Serving for human's daily life necessities, textile is one of the world's most important industries with the worth of its global industry estimated at US\$1 trillion worldwide. ${ }^{1}$ Due to continuously increasing global population, there has been a substantial expansion of such industry around the world. During textile processing, a variety of dyes is discharged into water effluent on a large scale, estimated to account for more than $35 \%$ of chemicals released in the environment. ${ }^{2}$ As a result, there have been great and wide concerns on water pollution and its impact on the environment, as compounds within dyes e.g. aromatics, metals and chlorides are potentially toxic to living organisms, including aquatic life and humans. Therefore, it is very important that dye-contaminated water effluents are properly treated before their discharge into the water environment. So far, various methods have been developed to treat dye wastewater e.g. membrane filtration, chemical treatment, incineration, adsorption and biological oxidation. Amongst these methods, adsorption on porous materials is being considered as a promising approach, because of its simplicity, low cost and ease of operation.

(SBUs) with organic ligands through coordinate covalent bonds, have been widely investigated, because of their excellent physicochemical property as adsorbents. Up to now, research studies have been conducted on several MOFs e.g. MIL-53, ${ }^{3} \mathrm{MIL}-100,{ }^{4} \mathrm{MIL}-101,{ }^{5} \mathrm{HKUST}-1,{ }^{6}$ $\mathrm{CuBTC}^{7}$ and UiO-66. ${ }^{8}$ However, regardless of their high performance in liquid adsorption, the stability of MOFs under aqueous solution is undoubtedly another important factor that has to be taken into consideration. Among all previously investigated MOFs, UiO-66 is the most promising candidate for dye removal in aqueous solution, as its crystallinity could be retained after aging in water up to 12 months. ${ }^{9}$

UiO-66 $\left(\mathrm{Zr}_{6} \mathrm{O}_{4}(\mathrm{OH})_{4}(\mathrm{BDC})_{12}\right)$ is a zirconium based MOF made up of $\left[\mathrm{Zr}_{6} \mathrm{O}_{4}(\mathrm{OH})_{4}\right]$ SBUs linked with 1,4-benzenedicarboxylic acid. Because of its structure, UiO-66 exhibits a large surface area, excellent pore volume and high thermal, chemical and mechanical stability. As a result, it can endure strong basic and acidic solutions as well as organic solvents and thereby having great potential in wastewater treatment. So far, the adsorption performance of UiO-66 has been investigated on several dyes. ${ }^{8-17}$ In addition to dye types, the adsorption capacity is also directly influenced by UiO-66 intrinsic properties, including electrostatic interactions, hydrogen bonding, acid-base interactions, $\pi-\pi$ interaction, hydrophobic interaction and pore/size selective adsorption. As such, a number of attempts have been made in order to gain an understanding of how these properties affect the adsorption process and thus find possible ways to improve the adsorption performances of Ui0-66. Previous attempts include (1) use of novel synthesis process (2) introduction of mixed metal into SBUs (3) introduction of mixed ligand into framework (4) alteration of the surface charge by attachment of acidic/basic molecules and (5) variation of the ligand's functional group.

The concept of mixed-component metal-organic framework (MC-MOFs) is a worth investigating option for enhancing UiO-66 adsorption performance. As MOFs have tunable porosities and thus they can be tailor-made to have heterometallic SBUs or different ligands connected to SBUs. By modification of metals or ligands, synthesized MC-MOFs could offer multifunctionality as well as their intrinsic properties could be fine-tuned to be suitable for specific application. Simply, MC-MOFs can be classified into 2 major groups, i.e. (1) mixed-metal (MM-MOFs) and (2) mixed-ligand MOFs (ML-MOFs). While the former is defined as those MOFs having more than one metal somewhere in their structure, the latter is referred to those having more than one type of ligand in the framework. ${ }^{18}$ Due to the synergy that could derive from the presence of mixed components, several studies reported superior performance of MC-MOFs in dye adsorption, compared to mono-component MOFs.

In the case of UiO-66, better performance for dye adsorption by its MM-MOFs have been reported when the insertion of $\mathrm{Ce}$ (III) or Ti(IV) ions was made into the material framework. ${ }^{10,16}$ In contrast, there is still no study made to investigate its mixed-ligand performance on the dye removal from aqueous solution, which thus became the aims of this study. 
In this study, mixed ligand UiO-66 (ML-UiO-66) was synthesized by variation of ligands between $\mathrm{BDC}$ and $\mathrm{BDC}^{\mathrm{N}} \mathrm{H}_{2}$ (ATA) in the molar ratio of $1: 0,0.5: 0.5,0.25: 0.75$ and 1:0 and then characterized by several techniques. The dye adsorption performance of all synthesized MOFs were examined using indigo carmine (IC), the organic compound that most commonly associated with the production of denim cloth and blue jeans. Up to our best knowledge, this is the first time investigation on IC removal from aqueous solution by UiO-66 and its mixed ligand derivatives. The adsorption parameters, adsorption isotherms, adsorption kinetics, and adsorption thermodynamics of all synthesized materials were also studied in order to investigate an effect of mixed ligand approach on UiO-66 adsorption capacity. Based on collected parameters and simulation results, the possible mechanisms of adsorption process in all adsorbents were also proposed and discussed.

\section{Experimental Section}

\subsection{Syntheses of the adsorbents}

\subsubsection{UiO-66}

UiO-66 was synthesized according to the previously reported procedure. ${ }^{19}$ All chemicals including zirconium chloride, 1, 4-benzenedicarboxylic acid (bdc) and $N$, $N$-dimethylformamide (DMF) were purchased from commercial vender and used without prior purification. UiO-66 was prepared via a solvothermal route without using any modulator. UiO-66 was made by mixing $0.7768 \mathrm{mg} \mathrm{ZrCl}_{4}$ with $0.5538 \mathrm{~g}$ of bdc in $20.0 \mathrm{~mL}$ of DMF. The mixture was placed in a $45 \mathrm{~mL}$ Teflon-liner stainless steel autoclave and heated to $120^{\circ} \mathrm{C}$ for 24 hours. The reaction vessel was left to cool down naturally to room temperature before the white fine powder product was filtered. The product was eventually washed several times with DMF and methanol before drying in the oven at $70^{\circ} \mathrm{C}$ overnight. To activate the sample, $1.000 \mathrm{~g}$ of as-made materials was treated with $20 \mathrm{~mL}$ of methanol overnight and recovered by filtration. The as-made material was calcined at $573 \mathrm{~K}$ for 12 hours under ambient condition. The calcined samples were stored in a desiccator until used.

\subsubsection{UiO-66-ATA}

UiO-66-ATA is isostructural to Ui0-66 and then its synthetic process was conducted using the similar procedure to that of UiO-66. The only difference was the use of $0.6038 \mathrm{~g}$ of 2-amino-1, 4-benzenedicarboxylic acid (ATA), instead of bdc. Similarly, ATA was also purchased from commercial vendors and used without prior purification. The sample was also activated using the above mentioned procedure in 2.1 .1 , but with calcined temperature of $493 \mathrm{~K}$.

\subsubsection{Mixed ligand-UiO-66}

In this study, two types of mixed-ligand Ui0-66, i.e. Ui0-66-0.5ATA and Ui0-66-0.75ATA, were synthesized. Specifically, the former was prepared by mixing $0.7768 \mathrm{mg} \mathrm{ZrCl}_{4}$ with $0.2769 \mathrm{~g}$ of bdc and $0.3019 \mathrm{~g}$ of ATA in $20.0 \mathrm{~mL}$ of DMF. For the latter, the same quantity of ZrCl 4 and DMF were used but with $0.1385 \mathrm{~g}$ and $0.4529 \mathrm{~g}$ of bdc and ATA respectively. For sample activation, the similar procedure as $2.1 .1 \mathrm{was}$ employed, but with some modified conditions. Specifically, calcined temperature of $493 \mathrm{~K}$ and heating duration of 9 hours were implemented for UiO-660.5ATA, where the temperature of $473 \mathrm{~K}$ and the duration of 12 hours were used for UiO-66-0.75ATA.

\subsection{Characterization of synthesized adsorbents}

In this study, several techniques were employed for characterizing all of synthesized MOFs. Firstly, the successful synthesis of product samples was confirmed by powder X-ray diffraction patterns (PXRD) using powder X-ray diffractometer (X'Pert MPD, Philips, USA) equipped with Cu $\mathrm{K}_{\mathrm{a}}$ radiation $(\lambda=0.15406 \mathrm{~nm})$. The PXRD patterns were collected in the $2 \theta$ range of $3^{\circ}-60^{\circ}$ at a step size of $0.03^{\circ}$ and a scan speed of $1.8^{\circ}$ min. Obtained PXRD patterns were compared with the simulated pattern calculated with Mercury 3.9 by using the unit cell parameter obtained from the previous work.[1] Secondly, crystal morphology of the samples was observed using a field-emission scanning electron microscope (Merlin compact, Carl Zeiss, Germany). Thirdly, thermal behavior and decomposition temperature of the samples were investigated using thermal analyzer. The thermogravimetric plots were collected at a temperature range of $50.0-800.0^{\circ} \mathrm{C}$ with a heating rate of $10^{\circ} \mathrm{C} / \mathrm{min}$. In addition, intrinsic character of samples, including surface area, pore size and pore volume, were investigated using $\mathrm{N}_{2}$ adsorption/ desorption isotherms. The materials were degassed at $423 \mathrm{~K}$ under high vacuum for 12 hours before performing the data collection which was done using a surface area and porosity analyzer (ASAP2460, Micromeritics, USA).

\subsection{Dye adsorption experiments}

Indigo carmine (IC) stock solution was prepared at a concentration of $1 \mathrm{~g} / \mathrm{L}$ and stored at room temperature. Successive dilution of the stock solution with deionized water was used to prepared IC solution at various concentration. Optimum parameters such as $\mathrm{pH}$, adsorbent dose, initial dye concentration and contact time were determined. Every experiments used $10.000 \mathrm{mg}$ of the adsorbent in $10.000 \mathrm{~mL} \mathrm{IC}$ solution. $\mathrm{pH}$ of the solution was fixed at 6.50. The well-mixed condition between IC solutions and the adsorbents was ensured using the incubator shaker, which operated at a fixed shaking rate of $200 \mathrm{rpm}$ and a fixed temperature of $303 \mathrm{~K}$. The mixtures were left overnight until reaching

Page $3 / 18$ 
equilibrium. IC solution after adsorption was acheived by centrifugation at 3,000 rpm for 5 minutes. UV-Vis spectrophotometer (Model 1205, Unico, USA) was used to determined the absorbance at $464 \mathrm{~nm}$, which was later used for the calculation of IC solution. The obtained data from adsorption studies were used for fitting with several kinetic models including pseudo-first-order, pseudo-second-order and Elovich kinetic model, where the rate limiting step and diffusion mechanism of IC adsorption by all the adsorbents were analyzed using intra-particle diffusion model (IPD) [2] and Boyd kinetic [3]. The change of adsorption capacity with initial concentration at selected temperatures were fitted with Langmuir, ${ }^{20}$ Freundlich, ${ }^{21}$ Dubunin-Radhsbkevish (D-R) and Temkin isotherm. Later on, adsorption thermodynamics parameters including enthalpy $(\Delta H)$, entropy $(\Delta S)$, and Gibbs free energy $(\Delta G)$ for all four MOFs under 303,313 , and $323 \mathrm{~K}$, were calculated.

\subsection{Computational details}

All possible SBU structures of UiO-66, UiO-66-0.5ATA, UiO-0.75ATA and UiO-66-ATA which are $\left[\mathrm{Zr}_{6} \mathrm{O}_{4}(\mathrm{OH})_{4}\left(\mathrm{OOC}_{-} \mathrm{C}_{6} \mathrm{H}_{4}-\mathrm{COO}\right)_{12}\right]^{12-}$, $\left[\mathrm{Zr}_{6} \mathrm{O}_{4}(\mathrm{OH})_{4}\left(\mathrm{OOC}-\mathrm{C}_{6} \mathrm{H}_{4}-\mathrm{COO}\right)_{6}\left(\mathrm{OOC}-\mathrm{C}_{6} \mathrm{H}_{6} \mathrm{~N}-\mathrm{COO}\right)_{6}\right]^{12-},\left[\mathrm{Zr}_{6} \mathrm{O}_{4}(\mathrm{OH})_{4}\left(\mathrm{OOC}-\mathrm{C}_{6} \mathrm{H}_{4}-\mathrm{COO}\right)_{3}\left(\mathrm{OOC}-\mathrm{C}_{6} \mathrm{H}_{6} \mathrm{~N}-\mathrm{COO}\right)_{9}\right]^{12-}$ and $\left[\mathrm{Zr}_{6} \mathrm{O}_{4}(\mathrm{OH})_{4}\left(\mathrm{OOC}-\mathrm{C}_{6} \mathrm{H}_{6} \mathrm{~N}-\right.\right.$ $\left.\mathrm{COO})_{12}\right]^{12-}$ respectively, were created and optimized at PM6 level of theory. The optimized structures (Figure S11) were then subjected to excited-state calculations using TD-DFT calculations at PBE1PBE/LanL2DZ level of accuracy. All calculations were performed by Gaussian09 program package. ${ }^{22}$ Additionally, the orbitals of the highest occupied molecular orbital (HOMO) and lowest unoccupied molecular orbitals (LUMO) of all structures (Figure S12) were generated by GaussView 5.0 program. ${ }^{23}$

\section{Results And Discussions}

\subsection{Characterization of UiO-66 and its analogues}

By using powder X-ray diffractometer, PXRD patterns of UiO-66, UiO-66-0.5ATA, UiO-66-0.75ATA and UiO-66-ATA were constructed and present in Fig. 1 (a). From the figure, a good match between PXRD pattern of UiO-66 sample and that of UiO-66 simulated from crystallographic data, obtained from the literature (cubic, space group: Fm-3m with $a=20.7004(2) \AA$ and $Z=1$ ) was observed and thus confirmed the successful synthesis of the compound. ${ }^{19}$ In addition, PXRD patterns of two mixed ligand UiO-66 (i.e. UiO-66-0.5ATA and UiO-66-0.75ATA) and UiO-66-ATA also correspond well with that of UiO-66 sample as well as the simulated one, suggesting they all are isostructural to UiO-66. Further confirmation was made by employing FTIR spectroscopy as shown in Fig. 1 (b). From the figure, IR spectra of both IC dye and adsorbents before and after adsorption are presented. The spectra of all 4 pre-adsorbed MOFs show characteristic peaks, which confirms the formation of the framework. Specifically, these peaks include two locations at about $660 \mathrm{~cm}^{-1}$ and $700-900 \mathrm{~cm}^{-1}$, which represent $\mu^{3}-\mathrm{OH}$ and Zr-O stretching vibration, respectively. Additionally, two strong peaks at 1400 and $1590 \mathrm{~cm}^{-1}$, representing asymmetric stretching in OCO and symmetric stretching in $O C O$, and one small peak at about $1500 \mathrm{~cm}^{-1}$, representing vibration of $\mathrm{C}=\mathrm{C}$ in a benzene ring, are also observed. The successful synthesis of the two mixed ligand UiO-66 and UiO-66-ATA was also confirmed, as the IR spectra show characteristic peaks at 1255 together and $1370 \mathrm{~cm}^{-1}$, representing $\mathrm{C}-\mathrm{N}$ stretching in the aromatic carbon and nitrogen, and $1622 \mathrm{~cm}^{-1}$, representing N-H bending vibration, all of which belong to the chemical characteristic of ATA ligands. After IC adsorption, the spectra of all four materials display characteristic peaks of IC dye e.g. asymmetric and symmetric S-O stretching vibrations at 1031 and $1105 \mathrm{~cm}^{-1}$ and asymmetric stretching vibration in $\mathrm{S}=0$ at 1323 and $1369 \mathrm{~cm}^{-1}$. As a result, these confirm the adsorption of IC molecules onto the adsorbent. In addition, the confirmation can be made by observing changes in the spectral intensity. Noticeably, the transmittance intensity of the O-C-O vibration and the N-H vibration becomes decreased after IC adsorption, thereby suggesting that there are adsorbent-adsorbate interactions.

Thermal stability of all four MOFs was investigated using TGA and the result is illustrated in Fig. 1 (c). The figure shows that all materials have similar TGA patterns, which can be divided into three distinct temperature regions. For the first one, from temperature of 298 to $373 \mathrm{~K}$, displays sharp and initial drops in weight percentage of samples, corresponding to the loss of water or methanol molecules, caused by vaporization. The second range, from 373 to $648 \mathrm{~K}$, show nearly flat profiles, which imply an absence of guest molecules and thus confirm the successful material activation. Reasonably, the weight loss during this region is attributed to the dehydroxylation of the zirconium oxoclusters. Following, the third region is marked by another significant weight loss, which is the indicator of the organic ligand departure or the framework decomposition. Notably, the thermal stability of MOFs appears to become decreased as the loading of ATA linkers in the MOFs increases. Numerically, the decomposition temperature of UiO-66, UiO-66-0.5ATA, UiO-66-0.75ATA and UiO-66-ATA were determined to be 700, 653,613 and $573 \mathrm{~K}$, respectively. These observations are in an agreement with previous study, which reported the decreasing trend of MOFs thermal stability with the rising number of ATA ligand. ${ }^{24}$

In addition, results from TGA analysis also enable an estimation of missing organic linker numbers by comparing the weight loss percentage occurring during the last region. As labelled on Fig. 1 (c), the actual loss of UiO-66, UiO-66-0.5ATA, UiO-66-0.75ATA and UiO-66-ATA are found to be 36, 30, 40 and 30\%, respectively, all of which are lower than theoretical loss that could be observed in the perfect UiO-66 (54\%) or UiO-66ATA (57\%). The differences in loss values could be rationalized by the defect of either missing ligand or cluster. Nevertheless, the latter can be eliminated, as our PXRD, Fig. 1 (a), shows no characteristic peak at $2 \theta$ of 2-7 degrees. Subsequently, it infers missing ligand defects as cause 
of discrepancies, which is consistent with previous study. ${ }^{25}$ The ligand weight loss found in UiO-66 sample is also in a good agreement with previous reports, which indicate the missing of one from the total of 12 ligands. ${ }^{26}$ However, for the rest of materials, the comparison was not possible, due to uses of different synthetic procedure and conditions, both of which are known to essentially influence the degree of material defects. Specifically, our used synthesis was carried out without adding any modulator, while it was employed by others.

By employing elemental analysis, there was a possibility to make the calculation on the number of ATA substitution in the framework, following the method proposed by Ferreira et. al. ${ }^{24}$ The calculated results are tabulated in Table 1, whereas our detailed calculation can be found in the supporting information. It has been observed from the table that the higher the amount of ATA ligands, the higher the amount of nitrogen mass percentage. The molar proportion of the functionalized linker (\%func) of Ui0-66-0.5ATA and UiO-66-0.75ATA were determined and found to be 59.20 and $82.89 \%$, respectively. The mismatch between experimental molar proportion from and its set value could be hypothesized from the random missing ligand vacancy in the materials, whose missing ligands might be BDC rather than ATA. The carbon mass percentage in each material is also shown in Table 1. Again, a small difference in carbon mass percentage between the experimental and theoretical values of each material could come from the number of missing ligands that cannot be identified.

Table 1

Molar fraction and mass amount of organic linkers used in each sample, mass percentage of carbon (\%C) and nitrogen $(\% \mathrm{~N})$ obtained from $\mathrm{CHON} / \mathrm{S}$ elemental analysis and calculated experimental molar proportion of the functionalized linker (\% func $)^{24,27}$

\begin{tabular}{|c|c|c|c|c|c|c|c|}
\hline Samples & $\mathrm{X}_{\mathrm{BDC}}$ & $\mathrm{m}_{\mathrm{BDC}}(\mathrm{g})$ & $X_{\text {ATA }}$ & $\mathrm{m}_{\mathrm{ATA}}(\mathrm{g})$ & $\begin{array}{l}\text { \%C exp } \\
\text { (Theoretical \%C) }\end{array}$ & $\begin{array}{l}\% \mathrm{~N} \\
\text { (Theoretical \%N) }\end{array}$ & \%func \\
\hline UiO-66 & 1 & 0.5538 & 0 & 0 & $\begin{array}{l}25.827 \pm 0.036 \\
(24.17)\end{array}$ & - & 0 \\
\hline UiO-66-0.5ATA & 0.5 & 0.2769 & 0.5 & 0.3019 & $\begin{array}{l}25.850 \pm 0.046 \\
(23.72)\end{array}$ & $\begin{array}{l}2.232 \pm 0.005 \\
(1.73)\end{array}$ & 59.20 \\
\hline UiO-66-0.75ATA & 0.25 & 0.1385 & 0.75 & 0.4528 & $\begin{array}{l}27.886 \pm 0.019 \\
(23.58)\end{array}$ & $\begin{array}{l}3.371 \pm 0.022 \\
(2.29)\end{array}$ & 82.89 \\
\hline Ui0-66-ATA & 0 & 0 & 1 & 0.6038 & $\begin{array}{l}25.888 \pm 0.044 \\
(23.29)\end{array}$ & $\begin{array}{l}3.884 \pm 0.046 \\
(3.40)\end{array}$ & 100 \\
\hline
\end{tabular}

To assess porosity of synthesized materials, BET surface area analysis was conducted before and after IC adsorption. From Fig. 1 (d), it can be seen that the nitrogen isotherms of all four materials follow IUPAC type IV isotherm, thereby confirming the presence of mesopores in their frameworks. From Table 2, the parent UiO-66 was found to have a BET surface area of $1281.6 \mathrm{~m}^{2} / \mathrm{g}$ and a total pore volume of $0.4596 \mathrm{~cm}^{3} / \mathrm{g}$, both of which are highly consistent with values previously reported in the literature for UiO-66 synthesized without using any modulator. ${ }^{19,28}$ In addition, the surface area of materials is observed to have a decreasing trend with an increasing number of ATA ligands connected to the framework, as that of UiO-66-0.5ATA, UiO-66-0.75ATA and UiO-66-ATA were determined to be $877.1,579.4$ and $441.9 \mathrm{~m}^{2} / \mathrm{g}$, respectively. This is in fact expected, since higher number of ATA means more $\mathrm{NH}_{2}$ group, which can protrude into the micropores of the MOFs and thus lead to the subsequent lower surface area. ${ }^{25}$

Table 2

The BET surface areas, pore sizes and pore volumes of UiO-66, UiO-66-0.5ATA, UiO-66-0.75ATA and UiO-66-ATA before and after IC adsorption

\begin{tabular}{|c|c|c|c|c|c|c|}
\hline \multirow[t]{2}{*}{ Sample } & \multicolumn{3}{|l|}{ Before adsorption } & \multicolumn{3}{|l|}{ After IC adsorption } \\
\hline & $\begin{array}{l}\text { BET surface area } \\
\left(\mathrm{m}^{2} / \mathrm{g}\right)\end{array}$ & Pore size $(\AA)$ & Pore volume $\left(\mathrm{cm}^{3} / \mathrm{g}\right)$ & $\begin{array}{l}\text { BET surface area } \\
\left(\mathrm{m}^{2} / \mathrm{g}\right)\end{array}$ & Pore size (Å) & Pore volume $\left(\mathrm{cm}^{3} / \mathrm{g}\right)$ \\
\hline UiO-66 & 1281.6 & 14.34 & 0.4596 & 389.7 & 70.20 & 0.6839 \\
\hline UiO-66-0.5ATA & 877.1 & 20.59 & 0.4515 & 711.8 & 21.80 & 0.3880 \\
\hline UiO-66-0.75ATA & 579.4 & 46.3 & 0.6704 & 708.3 & 40.66 & 0.7200 \\
\hline UiO-66-ATA & 441.9 & 22.11 & 0.2442 & 512.26 & 22.78 & 0.2918 \\
\hline
\end{tabular}

Unlike UiO-66, it has been found that obtained surface area of Ui0-66-0.5ATA, Ui0-66-0.75ATA and UiO-66-ATA are smaller than those from literature in the order of 1.4, 2.1 and 2.6-folds respectively. These discrepancies are most likely due to differences in synthetic and activation methods employed in this and other studies. ${ }^{29,30}$ For post-adsorption, BET surface area of both UiO-66 and UiO-66-0.5ATA becomes decreased 
with factors of c.a. 3.3 and 1.23 times lower than those of pre-absorbed counterparts, respectively. In contrast, there were c.a. 1.2-fold increases in surface area of post-absorbed UiO-66-0.75ATA and UiO-66-ATA. The significant reduction in UiO-66 surface area could be resulted from partial damages of MOF structure, which were induced during adsorption process, as well as the pore-filling effect of IC on the macropores between MOF particles. In addition, there could be serious pore blockage by large quantities of IC onto UiO-66 surface, thereby making the micropores in MOF crystals become no longer accessible for $\mathrm{N}_{2}$ adsorption. Since the average pore size of the material was found to become increased after adsorption, the blocked pores would be micropores, resulting in a decrease of specific surface area. For UiO-660.5ATA, similar rationales could be used as an explanation for the material reduced area. Nevertheless, its less degree of reduction could be resulted from the loss of ATA ligands during adsorption process, which then led to wider pore entrance and subsequent higher surface area of post-absorbed material. This metal-ligand breakdown is prone to be induced by the attack of water, as stability of ML-UiO-66 and UiO-66-ATA are less stable. ${ }^{31}$ Our hypothesis was supported by increased surface area obtained in post-adsorbed UiO-66-0.75ATA and UiO-66-ATA, whose pre-absorbed structures have the higher number of ATA ligands than that of UiO-66-0.5ATA.

\subsection{Adsorption parameters}

Adsorption behaviour of a particular adsorbent depends deeply with adsorption parameters including pH of dye solution, adsorbent concentration, initial dye concentration and contact time. Figure 2 (a), (c) and (d) show the effect of the first three adsorption parameters on adsorption behaviour of all studied adsorbents. Principally, $\mathrm{pH}$ has a direct influence on dye adsorption as its variation can stimulate the protonation or deprotonation of the adsorbents as well as the ionization of the dye molecules. Herein, an effect of solution pH on IC removal by synthesized MOFs was investigated in a range of 2 to 11 and the results are presented in Fig. 2 (a). It can be seen that all synthesized MOFs show similar trend in their adsorption behaviour toward a change of $\mathrm{pH}$, where the maximum adsorption capacity was observed at the lowest $\mathrm{pH}$ solution of 2.0. With increasing $\mathrm{pH}$, the adsorption capacities drop continuously until reaching the lowest adsorption capacity at a $\mathrm{pH}$ of 11. This suggests that electrostatic interaction plays a crucial role during adsorption. Reasonably, under lower $\mathrm{pH}$, there is a higher degree of $\mathrm{H}^{+}$presence in the solution, which in turns promotes the protonation of the absorbent and thus a positive-charged surface as evidenced by zeta potential measurement, as shown in Fig. 2 (b). Because of the negative-charged nature of IC, there is a greater electrostatic attraction between the dye molecules and protonated absorbents, resulting in a higher adsorption capacity. From zeta potential measurement, at a $\mathrm{pH}$ of 7, it is evidient that adsorbents containing ATA ligand bear more negative-charged surface compared to UiO-66. This results in a lower adsorption capacity at every observed $\mathrm{pH}$ found in UiO-66-ATA compared to that of UiO-66. However, when comparing adsorption capacity between UiO-66 and mixed component UiO-66, UiO-66-0.75ATA shows the highest adsorption capacity over all tested pH, regardless to its more negative charge in nature, while Ui0-66-0.5ATA shows higher adsorption capacity at some particular pH. This implies that, apart from electrostatic interaction, there must be other interactions involving during the adsorption process. Nevertheless, even at their lowest capacity, all the adsorbents still displayed relatively high IC removal in comparison with previous studies. ${ }^{32-34}$ Their high durability under a harsh pH condition was also ensured as evidenced from PRXD result, Fig. 1 (a)-inset, which shows good crystallinity of all materials, even after they were soaked in dye solution at $\mathrm{pH}$ of 11 for 24 hours. Subsequently, their application can be assured over a wide range of pH and also facilitate an ease of process operation, as there is no necessity for adjusting wastewater pH prior to the treatment. Lastly, it is found that IC uptake by all four MOFs follows the order of Ui0-66-0.75 > UiO-66-0.5ATA $\approx$ UiO-66> UiO-66-ATA at all the tested pH. Although the order is not completely aligned with the amount of ATA ligands in the MOFs, it clearly suggests that the mixed component MOF offer an alternative method for enhancing dye adsorption capacity.

To investigate the effect of adsorbent dosage on IC removal, the adsorption capacity of IC by four MOFs covering an initial dosage of 10 to $100 \mathrm{mg}$ was determined using an initial IC concentration of 100 mg/L. As shown in Fig. 2 (c), for all four MOFs, it can be seen that the IC removal percentage becomes enhanced with increasing adsorbent dosage until certain value of dosage, beyond which its further addition begins to have no enhancing effect on the removal. The certain value is called the "threshold dosage" and was found to be 30 mg for the two ML-UiO-66 and UiO-66, while that of UiO-66-ATA was determined to be $50 \mathrm{mg}$. In addition, it is apparent that the greatest degree of enhancement in IC removal by all adsorbents was obtained when their dosage was increased from 10 to $20 \mathrm{mg}$. After that, a gentle enhancement in removal was observed, as its percentage was slightly increased. This could be due to the effect of solid adsorbent agglomeration, which then diminishes the adsorbed surface sites. ${ }^{35}$ In case of UiO-66-ATA, agglomeration may have less effect, as the materials' frameworks contain amino groups on surface that may create repulsion forces between particles and hence result in more disperse character.

In this study, the effect of IC initial concentration of $50-300 \mathrm{mg} / \mathrm{L}$ on MOFs adsorption capacity was also determined and its result is presented in Fig. 2 (d). From the figure, it can be seen that IC adsorption performance by all MOFs generally increases with increased dye concentration. UiO-66-0.75ATA is the most efficient IC absorbent among the four MOFs, covering a whole range of IC concentration. Meanwhile, UiO-66-ATA is the least efficient IC adsorbent. It is worthnoting that the IC removal percentage of all four adsorbent decreases with increasing IC concentration due to the limitation of the adsorption sites on the adsorbent surface.

\subsection{Adsorption kinetics}


The effect of contact time on IC removal by the four MOFs for initial IC concentration of $100 \mathrm{mg} / \mathrm{L}$ was investigated by varying the contact time from 0 to 1,440 minutes and its result is displayed in Fig. 3 (a). From the figure, it is clear that adsorption capacity of all MOFs can be enhanced by increasing contact time. Sharp rises in $Q_{e}$ during first contact time of 100 minutes were usually expected, as during the initial stage, absorbents still have plentiful number of free and vacant adsorption sites and thus can rapidly bind with dye molecules present in the solution. As the contact time proceeds, most of the sites become occupied and then rate of adsorption come to be slower and finally reach a certain value under the equilibrium. For a given IC concentration, a contact time of 480 minutes appears to be an appropriate duration for all MOFs, beyond which there is a marginal enhancement in $Q_{e}$ with time. Nevertheless, a complete equilibrium, where $Q_{e}$ becomes virtually constant, is most likely to be attained at the contact time of c.a. 920 minutes.

Adsorption kinetics are of great significance to evaluate the performance of a given absorbent and to gain an understanding of the underlying mechanisms, both of which control the overall process efficiency and thus are important for design of adsorption process facilities.

Fundamentally, the adsorption of liquid dyes using solid absorbent is composed of two sequential steps: (1) the migration of solutes from the bulk solution to the liquid layer adjacent to the adsorbent particle and (2) the diffusion of solutes through the layer until they reach the adsorption surface (film diffusion). Usually, the first step occurs very fast and thus the second step is the rate limiting step. However, in a porous adsorbent, an intraparticle diffusion, which particularly refers to the diffusion of solutes into the interior surface of the adsorbent, can also play a role as a rate controlling step.

The obtained data from IC adsorption kinetics by all four MOFs under different temperature i.e. 303,313 and $323 \mathrm{~K}$ and at initial IC concentration of 100 ppm were used for the detailed studies of adsorption kinetics using 5 models i.e. the pseudo-first order, pseudo-second order, Elovich, intraparticle diffusion model (IPD) and Boyd kinetic models. The former three were employed to examine the rate of adsorption of IC from the solution, while the rest of two models were selected to investigate intraparticle diffusion. The results from fitting our obtained data with models are summarized in Figure S2-5 and Table S1-3 in the Supporting Information.

It has been found that both pseudo-first-order and Elovich models are not suitable in describing IC adsorption kinetics, as poor linear correlation efficiency $\left(R^{2}<0.99\right)$ was observed for all of investigated cases, as shown in Table S1, 2, 3. On the other hand, pseudo-second-order model produced fittings with good quality $\left(R^{2}>0.99\right)$ as well as a very small difference between the experimental and theoretical adsorbed masses at equilibrium (less than 1\%), suggesting its effective simulation capacity and subsequent reliability. As a result, only parameters obtained from the latter model were used for further analysis and discussion. Figure 3 (b) illustrates the effect of temperature and IC concentration on pseudo-second order rate constant $\left(k_{2}\right)$ of each MOF. From the figure, it is clear that adsorption kinetics of all materials follow an increasing trend with the rise in temperature, suggesting dye adsorption process as an endothermic process. Since UiO-66-ATA was also found to have the highest rate constant at all three temperatures, this implies that a potential role of amino group in enhancing the rate of adsorption.

Another analysis made of obtained rate constant was to determine activation energy $\left(E_{a}\right)$ by employing the linear form of Arrhenius equation, which is a plot of In $k_{2}$ against 1/T, Fig. 3 (c). The slope of the plot was then computed to give $E_{a}$ for each MOF under IC concentration of 100 ppm. From the figure, it has been found that IC adsorption by UiO-66 has the highest value of $E_{a}$, c.a. $33 \mathrm{~kJ}^{\mathrm{mol}}{ }^{-1}$, while the rest of three materials have similar $E_{a}$ values in a range of c.a. $17-22 \mathrm{~kJ} \mathrm{~mol}^{-1}$. Since any reaction with Ea value above $120 \mathrm{~kJ}^{\mathrm{mol}}-1$ generally occurs rather slowly, ${ }^{36}$ it thus implies that IC adsorption by all studied MOFs can be classified as a relatively quick reaction. As an apparent reduction in Ea values can be observed when ATA ligands were introduced into UiO-66 framework, it then suggests that amino groups play a vital role in lowering the activation energy of the adsorption process and subsequently enhancing the rate of reaction. Reasonably, amino groups may participate in the attachment of IC molecules during the transition state of adsorption, due to their ability to create hydrogen bonding.

Adsorption is a relatively complex process, which usually consists of several consecutive steps. To understand the mechanistic pathway of the IC adsorption in all four MOFs, it becomes necessary to firstly observe involved steps of the adsorption and eventually identify the rate limiting step. Figure 3 (d) shows the fitting of obtained data with the IPD model at $303 \mathrm{~K}$. From this model, if the plot of dye uptake, $Q_{t}$, versus the square root of time, $\mathrm{t}^{1 / 2}$, shows linearity, it means that intraparticle diffusion is involved in the adsorption system. Providing the linear plot passes through the origin; it also implies intraparticle diffusion as the rate-controlling step. From the figure, it has been found that the adsorption of all four adsorbents exhibit a linear correlation in 3 distinct regions. The first region corresponds to the film diffusion over the first 240 mins of adsorption. After this point, the adsorption process is governed by intraparticle diffusion, which consists of surface and pore diffusions, corresponding to region 2 and 3 in the plot respectively. Since the rate constants of first stage $\left(k_{1 d}\right)$ are higher than those of the second $\left(k_{2 d}\right)$ and the third stages $\left(k_{3 d}\right)$ in all four materials, as shown in Table S2, 3 and 4 in the Supporting Information, this finding suggests the potential of intraparticle diffusion being the rate-determining step. However, $R^{2}$ values of the fittings show a certain degree of deviation from linearity and the straight lines of each region do not pass through the origin. As a result, these indicate that intraparticle diffusion is not 
the only rate-limiting step, but there are also other steps that may play a role in controlling the rate of adsorption, all of which may be occurring simultaneously. ${ }^{37}$

As the conclusion cannot be made using solely IPD model, further analysis of the data using Boyd model was carried out. The plots of calculated $B_{t}$ versus time of IC adsorption by all four materials at each temperature are provided in Fig. S5 in the Supporting Information. The linearity of this plot can be used to distinguish between film diffusion and intraparticle-transport-controlled rate of adsorption. From Fig. S5, it can be observed that, under all of the studied conditions, the plots deviate from linearity and do not pass through the origin, thereby suggesting that film diffusion or external mass transport mainly governs the adsorption process and can be considered as rate-limiting step. Using the slope of the Boyd plot, values of two model parameters i.e. $B$ and effective diffusion coefficient, $D_{i}\left(\mathrm{~cm}^{2} / \mathrm{s}\right)$ were obtained and listed in Table S1, 2 and 3. Generally, if $D_{i}$ lies in the range $10^{-11}$ to $10^{-13} \mathrm{~cm}^{2} / \mathrm{s}$, intraparticle diffusion is then suggested as the rate determining step. Since $D_{i}$ values of all four materials are in a range of $1.33-6.09 \times 10^{-18}\left(\mathrm{~cm}^{2} / \mathrm{s}\right)$, which is around 6 order of magnitude lower, this implies that the intraparticle diffusion was not the only rate-controlling step, but there was also an involvement of film diffusion in controlling adsorption process of IC by synthesized MOFs. In comparison with literature, the $D_{i}$ values found in this study are in the same order of magnitude observed from the diffusion rate of organic molecules within other MOFs. ${ }^{38,39}$

\subsection{Adsorption isotherm}

To gain insights on distribution of dye molecules between solid and liquid phases at equilibrium state, the studies of adsorption isotherm were investigated by fitting our experimental data with four widely employed isotherm models, i.e. Langmuir, Freundlich, Dubunin-Radhsbkevish (D$\mathrm{R}$ ) and Temkin isotherm models under a given range of temperature. The results of fittings obtained from each model can be seen in Table 3.

In comparison between four models, Langmuir model is the simplest one, which can only describe the monolayer adsorption in a finite number of homogenous surface, while Freundlich model is more applicable to a multilayer adsorption on heterogeneous surface that have unequal active sites with different binding energy. For D-R and Temkin models, they are usually employed to differentiate the type of adsorption mechanism whether the process is physisorption or chemisorption. By obtaining the isotherm knowledge, the prediction of adsorption capacity and behavior becomes possible and can be used further to elucidate the mechanism of dye adsorption process. 
Table 3

Adsorption isotherms parameters of IC adsorption on to UiO-66, UiO-66-0.5ATA, UiO-66-0.75ATA and UiO-66-ATA for Langmuir, Freundlich, Dubunin-Radhsbkevish and Temkin models at different temperatures.

\begin{tabular}{|c|c|c|c|c|c|c|c|c|c|c|c|c|}
\hline \multirow{2}{*}{$\begin{array}{l}\text { Langmuir } \\
\text { isotherm }\end{array}$} & \multicolumn{3}{|l|}{ Ui0-66 } & \multicolumn{3}{|c|}{ Ui0-66-0.5ATA } & \multicolumn{3}{|c|}{ Ui0-66-0.75ATA } & \multicolumn{3}{|c|}{ Ui0-66-ATA } \\
\hline & $303 \mathrm{~K}$ & $313 \mathrm{~K}$ & $323 \mathrm{~K}$ & $303 \mathrm{~K}$ & $313 \mathrm{~K}$ & $323 \mathrm{~K}$ & $303 \mathrm{~K}$ & $313 \mathrm{~K}$ & $323 \mathrm{~K}$ & $303 \mathrm{~K}$ & $313 \mathrm{~K}$ & $323 \mathrm{~K}$ \\
\hline$Q_{0}(\mathrm{mg} / \mathrm{g})$ & 135.14 & 303.03 & 454.55 & 60.24 & 175.44 & 192.31 & 227.27 & 192.31 & 175.44 & 60.61 & 196.08 & 208.33 \\
\hline$b(L / g)$ & 0.029 & 0.032 & 0.024 & 0.032 & 0.059 & 0.079 & 0.075 & 0.077 & 0.100 & 0.026 & 0.040 & 0.056 \\
\hline $\mathrm{R}_{\mathrm{L}}$ & 0.26 & 0.24 & 0.30 & 0.24 & 0.14 & 0.11 & 0.12 & 0.11 & 0.09 & 0.28 & 0.20 & 0.15 \\
\hline$R^{2}$ & 0.9930 & 0.9724 & 0.9975 & 0.9930 & 0.9910 & 0.9907 & 0.9966 & 0.9987 & 0.9969 & 0.9993 & 0.9994 & 0.9992 \\
\hline \multirow{2}{*}{$\begin{array}{l}\text { Freundlich } \\
\text { isotherm }\end{array}$} & \multicolumn{3}{|l|}{ UiO-66 } & \multicolumn{3}{|c|}{ Ui0-66-0.5ATA } & \multicolumn{3}{|c|}{ UiO-66-0.75ATA } & \multicolumn{3}{|c|}{ UiO-66-ATA } \\
\hline & $303 \mathrm{~K}$ & $313 \mathrm{~K}$ & $323 \mathrm{~K}$ & $303 \mathrm{~K}$ & $313 \mathrm{~K}$ & $323 \mathrm{~K}$ & $303 \mathrm{~K}$ & $313 \mathrm{~K}$ & $323 \mathrm{~K}$ & $303 \mathrm{~K}$ & $313 \mathrm{~K}$ & $323 \mathrm{~K}$ \\
\hline$K_{F}(\mathrm{mg} / \mathrm{g})$ & 20.82 & 12.33 & 12.11 & 10.83 & 16.04 & 20.17 & 25.78 & 17.68 & 22.46 & 11.73 & 12.65 & 23.34 \\
\hline$n$ & 2.99 & 1.36 & 1.20 & 3.32 & 1.80 & 1.79 & 2.10 & 1.65 & 1.93 & 3.49 & 1.63 & 2.02 \\
\hline$R^{2}$ & 0.9927 & 0.9941 & 0.9956 & 0.9867 & 0.9736 & 0.9721 & 0.965 & 0.9631 & 0.9372 & 0.9819 & 0.9818 & 0.9891 \\
\hline \multirow{2}{*}{$\begin{array}{l}\text { Dubunin- } \\
\text { Radushkevich } \\
\text { isotherm }\end{array}$} & \multicolumn{3}{|l|}{ UiO-66 } & \multicolumn{3}{|c|}{ Ui0-66-0.5ATA } & \multicolumn{3}{|c|}{ UiO-66-0.75ATA } & \multicolumn{3}{|c|}{ UiO-66-ATA } \\
\hline & $303 \mathrm{~K}$ & $313 \mathrm{~K}$ & $323 \mathrm{~K}$ & $303 \mathrm{~K}$ & $313 \mathrm{~K}$ & $323 \mathrm{~K}$ & $303 \mathrm{~K}$ & $313 \mathrm{~K}$ & $323 \mathrm{~K}$ & $303 \mathrm{~K}$ & $313 \mathrm{~K}$ & $323 \mathrm{~K}$ \\
\hline$Q_{m}(\mathrm{mg} / \mathrm{g})$ & 101.49 & 157.43 & 175.56 & 51.99 & 131.76 & 141.32 & 176.09 & 143.31 & 134.83 & 44.08 & 133.49 & 143.02 \\
\hline $\mathrm{E}(\mathrm{kJ} / \mathrm{mol})$ & 0.10 & 0.18 & 0.21 & 0.06 & 0.17 & 0.24 & 0.16 & 0.25 & 0.30 & 0.46 & 0.49 & 0.21 \\
\hline$R^{2}$ & 0.9000 & 0.9394 & 0.9525 & 0.9059 & 0.9159 & 0.8887 & 0.8852 & 0.9159 & 0.8688 & 0.9160 & 0.9380 & 0.9255 \\
\hline \multirow{2}{*}{$\begin{array}{l}\text { Temkin } \\
\text { isotherm }\end{array}$} & \multicolumn{3}{|l|}{ UiO-66 } & \multicolumn{3}{|c|}{ Ui0-66-0.5ATA } & \multicolumn{3}{|c|}{ UiO-66-0.75ATA } & \multicolumn{3}{|c|}{ UiO-66-ATA } \\
\hline & $303 \mathrm{~K}$ & $313 \mathrm{~K}$ & $323 \mathrm{~K}$ & $303 \mathrm{~K}$ & $313 \mathrm{~K}$ & $323 \mathrm{~K}$ & $303 \mathrm{~K}$ & $313 \mathrm{~K}$ & $323 \mathrm{~K}$ & $303 \mathrm{~K}$ & $313 \mathrm{~K}$ & $323 \mathrm{~K}$ \\
\hline$B$ & 28.01 & 66.22 & 79.54 & 11.77 & 34.60 & 37.43 & 46.69 & 34.48 & 34.87 & 13.56 & 46.61 & 48.08 \\
\hline$b(\mathrm{~J} / \mathrm{mol})$ & 89.93 & 39.30 & 33.76 & 213.96 & 75.20 & 71.75 & 53.96 & 67.63 & 77.01 & 185.72 & 55.83 & 55.86 \\
\hline$A(\mathrm{~L} / \mathrm{mg})$ & 0.33 & 0.3 & 0.32 & 0.45 & 0.79 & 1.06 & 0.68 & 0.97 & 1.27 & 0.24 & 0.33 & 0.49 \\
\hline$R^{2}$ & 0.9964 & 0.9767 & 0.9897 & 0.9804 & 0.9756 & 0.9743 & 0.9974 & 0.9791 & 0.9961 & 0.9997 & 0.9990 & 0.9988 \\
\hline
\end{tabular}

From Table 3, it has been found that Langmuir model can effectively describe the process of IC adsorption by three out of four MOFs i.e. UiO66-0.5ATA, UiO-66-0.75ATA and Ui0-66-ATA for a whole range of studied temperature with linear correlation coefficient $\left(R^{2}\right)$ values of at least 0.99. As a result, these observations suggest the monolayer-typed adsorption for these three materials. In case of UiO-66, although the model can fit well with data obtained at both 303 and $323 \mathrm{~K}$, there was slightly poorer quality of fitting at $313 \mathrm{~K}$ with $R^{2}$ of 0.9724 . The maximum values of dye adsorption capacity at equilibrium, $Q_{0}$, for UiO-66, UiO-66-0.5ATA and UiO-66-ATA, were all observed at $323 \mathrm{~K}$ and found to be $454.55,192.31$, and $208.33 \mathrm{mg} / \mathrm{g}$ respectively. In addition, as their values of $Q_{0}$ follow an increasing trend with rising temperature, it implies their adsorption processes as endothermic ones. In contrast, for Ui0-66-0.75ATA, the maximum $Q_{0}$ value of $227.27 \mathrm{mg} / \mathrm{g}$ was obtained at 303 $\mathrm{K}$ and its value was found to decrease with increasing temperature, thereby suggesting an exothermic reaction occurred during the IC adsorption process of the material. The " $b$ " parameter in the Langmuir model provides information of binding strength and the degree of interaction between the dye and the adsorbent surface. The table shows the common trends of the greater $b$ value with increasing temperature in all MOFs, except UiO-66, at which the reverse trend can be seen. In comparison among three MOFs, the order of their $b$ values follows: UiO66-0.75 > UiO-66-0.5-ATA > UiO-66-ATA for all of investigated temperatures. In other words, the model suggests that the IC adsorption is more favourable on the surface of UiO-66-0.75ATA than other two adsorbents. Separation factor, $R_{L}$, is another essential of Langmuir isotherm and can be used for predicting the affinity between adsorbate and adsorbent. As all of $R_{L}$ values determined from all four materials were found to lie between 0 and 1 (ranging from 0.09 to 0.30), the results then suggest favourable nature of IC adsorption process by all MOFs under given temperature range is favorable. Herein, a decreasing trend of $R_{L}$ with rising temperature was mutually observed in ML-UiO-66 and UiO-66-ATA, indicating the IC adsorption process to become more favourable at higher temperature. Again, the uncommon finding in UiO-66 could be rationalized as above mentioned. 
As the second choice of isotherm, Freundlich model was found to fit well with experiment data obtained from UiO-66 with all $R^{2}$ values of above 0.99 , but give poorer fitting result for the rest of three materials, as evidenced from lower $R^{2}$ values of below 0.99 , as shown in Table 3 . Therefore, this suggests Freundlich model as a more suitable one over the Langmuir for describing the IC adsorbing behavior of UiO- 66 as well as implies the heterogeneity of material surface with different binding energies on its surface. Besides, as the model cannot be used to effectively simulate the adsorption process of ML-UiO-66 and UiO-66-ATA, our discussion will be made related to solely UiO-66. With regard to the Freundlich model, there are two constants i.e. $n$ and $K_{F}$, which can provide an indication of adsorption intensity and capacity, respectively. Specifically, the value of $n$ determines the degree of nonlinearity between concentration of dye solution and its adsorption quantity in the 2 different ways: 1) if $n<1$, the adsorption process is chemisorption and 2) if $n>1$, the adsorption process is physisorption. ${ }^{32}$ As shown in the table, since $n$ values obtained from all studied conditions are all greater than 1, thereby implying the IC adsorption process by UiO-66 as physisorption rather than chemisorption process. In addition, the value of $1 / n$ can be used to infer a favourable adsorption under all of the experimental conditions, as its value is in between 0 and 1 . As both $K_{F}$ and $1 / n$ display an increasing profile with increasing temperature, it then indicates a more favourable adsorption process at higher temperature. These findings in UiO-66 are essentially similar to ones previously observed in ML-UiO-66 and UiO-66-ATA using the Langmuir model.

Among four models, the worst fitting was clearly observed in D-R model, with none of $R^{2}$ values reaching 0.99 , thereby implying the model as invalid option for further investigation and discussion. For Temkin model, by considering all of $R^{2}$ determined, it can provide relatively good fitting with a comparable degree with that obtained from Freundlich model. Nevertheless, the results show UiO-66-ATA as the most suitable material, whose IC adsorption process can be described by the model, as, for this MOF, $R^{2}$ of the fittings are greater than 0.99 for all of studied temperatures. Since Temkin isotherm takes into account the effect of heat of adsorption through its constant " $b$ ", its good fittings in all four MOFs suggest IC adsorption process by materials to be highly dependent on this type of heat. Under our experimental specification, as all of $b$ values determined are less than $1 \mathrm{kcal} / \mathrm{mol}(4,184 \mathrm{~J} / \mathrm{mol})$, it then confirms the physisorption nature in UiO-66 adsorption, as previously revealed by Freundlich model, as well as suggests the same reaction nature for the process carried out by the rest of three materials. Lastly, the model also infers all of adsorption processes to be exothermic reactions, as all of $A$ values are positive.

\subsection{Adsorption thermodynamics}

To determine the spontaneity of adsorption processes from the view of energetic driving force, the study of IC adsorption thermodynamics was performed by calculation of enthalpy $(\Delta H)$, entropy $(\Delta S)$, and Gibbs free energy $(\Delta G)$ for all four MOFs under 303,313 , and $323 \mathrm{~K}$, all of which were listed on Table 4.

Table 4

Thermodynamics parameters for the adsorption of IC onto the UiO-66, UiO-66-0.5ATA, UiO66-0.75ATA and UiO-66-ATA

\begin{tabular}{|c|c|c|c|c|c|c|}
\hline \multirow[t]{2}{*}{ Adsorbent } & \multirow[t]{2}{*}{$\Delta H^{P}(\mathrm{~kJ} / \mathrm{mol})$} & \multirow[t]{2}{*}{$\Delta S^{\circ}(\mathrm{J} / \mathrm{mol} \mathrm{K})$} & \multicolumn{3}{|c|}{$\Delta G^{\circ}(\mathrm{kJ} / \mathrm{mol})$} & \multirow[t]{2}{*}{$R^{2}$} \\
\hline & & & $303 \mathrm{~K}$ & $313 \mathrm{~K}$ & $323 \mathrm{~K}$ & \\
\hline UiO-66 & 36.38 & 132.72 & -3.73 & -5.40 & -6.37 & 0.9708 \\
\hline UiO-66-0.5ATA & 79.39 & 270.65 & -2.17 & -6.30 & -7.52 & 0.9009 \\
\hline UiO-66-0.75ATA & 9.20 & 52.40 & -6.74 & -7.06 & -7.79 & 0.8646 \\
\hline UiO-66-ATA & 81.16 & 273.67 & -1.25 & -5.61 & -6.65 & 0.8802 \\
\hline
\end{tabular}

It has been revealed from the table that all of IC adsorption processes by synthesized materials are endothermically driven $(\Delta H>0)$, the finding at which is in line with the above mentioned in studies of adsorption kinetics and isotherm. This means that the IC adsorption process favors higher temperature, similar to what have been reported in other types of dyes adsorption by UiO-66 analogues. ${ }^{9}$ Reasonably, the increase in temperature not only enhances rate of adsorption reaction, but also provides more energy to dye molecules, making them become more energetic and can easily pass through the micropore of the adsorbent. ${ }^{40}$ Based on the value of $\Delta H$, the mechanism of adsorption process can also be inferred: 1) when $\Delta H$ is in the range of $8-65 \mathrm{~kJ} / \mathrm{mol}$, the adsorption process is physisorption and 2) when $\Delta H$ is in the range of $84-420 \mathrm{~kJ} / \mathrm{mol}$, the adsorption process is chemisorption. ${ }^{41}$ As a result, by following this criteria, the adsorption process in UiO-66 and UiO-66-0.75ATA is classified as physisorption. In case of both UiO-66-0.5ATA and UiO-66-ATA, as their values of $\Delta H$ do not fall into given criteria, but are greater than upper range of the physisorption, it then suggests their processes to be physicochemical reaction, potentially having chemisorption as a dominant mechanism. ${ }^{42}$ Having considered $\Delta S$, their positive values, which could be resulted from an increase of randomness at the solid/liquid interface accompanied with some structural changes in the dye molecules and the adsorbent surface, imply spontaneous adsorption processes in all adsorbents. The positivity of both $\Delta S$ and $\Delta H$ also suggests an entropic-driven adsorption process. The spontaneity of all studied processes was additionally confirmed by negative values of determined Gibbs free energy. In addition, as $\Delta G$ was found to become more negative with increasing temperature, this suggests that the degree of spontaneity in all reactions is dependent on

Page 10/18 
temperature and can be enhanced at higher temperature. The value of $\Delta G^{O}$ can also be used as an indicator to differentiate between

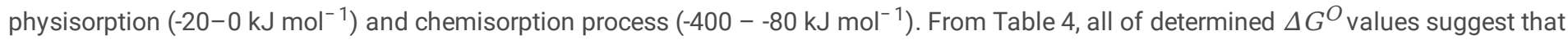
adsorptions of IC on all candidate materials are physisorption.

\subsection{Adsorption mechanism}

Having considered results obtained from all of above-mentioned studies, it gives us the possible mechanism that dictates the adsorption behaviour of IC onto synthesized adsorbents. The core factor that regulates the adsorption process is the surface interaction between adsorbent and adsorbate, which can be either physical or chemical force. In this study, the adsorption processes of IC by all four materials were found to be physisorption. In addition, IR spectra show no shift/extra in characteristic vibrational peaks, but rather the characteristic peaks of both adsorbents and IC dye together (Fig. 1 (b)). This means that IC dye molecules were adsorbed onto the adsorbent surface without forming chemical bonding. Since the attachment of IC molecules on UiO-66 surface has been discovered to be in a multilayer fashion, it suggests as uneven energy of the adsorption sites, which could be caused by partial ligand missing as observed in UiO-66. For ML-UiO-66 and UiO-66-ATA, adsorption of dye molecules occurred in a monolayer pattern, implying homogeneity of their surfaces. The finding of latter three opposes that of UiO-66, despite the fact that all of materials contain certain degrees of missing ligand. As such, it may be possible that the presence of amino groups in these three MOFs makes their surfaces with defect sites become more steric and then unreachable from approaching dye molecules. Once attached to the surface, it can be inferred that attached IC molecules remain on the surface, as dye molecular size is larger than an aperture of all adsorbents, resulting in disregard of pore/size selective adsorption. ${ }^{43}$

As there are several underlying forces e.g. electrostatic force, van der Waal interaction and $\pi-\pi$ stacking and hydrogen bonding in physisorption, it is crucial to identify the one that in fact dominates the process. Since adsorption of all four materials has been found to be $\mathrm{pH}$ dependent, this suggests electrostatic or acid-base interaction as potentially governing force. Due to anionic nature of IC dye, adsorbent surface with less negative nature can effectively facilitate electrostatic interaction and the subsequent adsorption. As evidenced in Fig. 2 (b), the zeta potential of ML-UiO-66 and UiO-66-ATA are close in magnitude and more negative than that of UiO-66, thereby suggesting the potential effect of amino groups in an induction of more negatively charged surface and subsequently greater repulsion force.

Acid-base interaction can occur in the adsorption process by MOFs, as the missing ligand defects of the materials leads to the generation of Lewis acid sites, which are later induced by water in dye solution to become both Bronsted acid/base sites, IC dye, which is a Bronsted base, then interact with these sites. ${ }^{44}$ The presence of amino groups was also reported to strengthen the bonding of water at the Bronsted acid sites, which could weaken acid-base interaction in ML-UiO-66 and UiO-66-ATA and give rise to their lower adsorption capacity, in comparison with UiO-66. As shown in Fig. 2 (a), the highest adsorption capacities of all four materials were obtained under the most acidic condition. In principle, this would have not been observed, if acid-base interaction was the dominant force. Reasonably, under highly acidic condition, IC molecules becomes completely protonated and thus can no longer have such interaction with absorbents. As a result, this indicates a small influence of acid-base interactions in respective adsorption performance.

The other possible interactions, including $\pi-\pi$ stacking and hydrogen bonding may also take part during the adsorption process. For $\pi-\pi$ stacking, the interaction can be formed in all four MOFs, since all materials have benzene rings, which can interact with quasiplanar IC molecules. In contrast, hydrogen bonding can only exist in the adsorption of MOFs containing amino groups i.e. ML-UiO-66 and UiO-66-ATA. Nevertheless, hydrogen bonding cannot be regarded as a main force, since the highest IC removal capacity was observed from UiO-66$0.75 \mathrm{ATA}$, the MOFs bearing some amino groups, as evidenced in Fig. 2 (a). Although, the presence of amino group does not give much benefits to adsorption capacity, it possibly assists the attachment of dye molecules on the surface of ML-UiO-66 and UiO-66-ATA, then resulting in their lower activation energy and faster adsorption rate, as shown in Fig. 3 (b) and (c).

To further investigate the effect of introduced ATA ligand upon the adsorption behavior, the study of orbital contributions in the adsorbents before and after adsorption (ground state and excited state) was carried out obtained using TD-DFT. In addition, HOMO and LUMO of one SBU-ligands cluster of all four materials were also investigated. Previously, the method was employed with successful investigation of UiO-66 and its analogue under light absorption. ${ }^{45}$

From Fig. 4 (a) as well as supplementary info, it can be seen that HOMO in all four adsorbents wee localized on the organic linker. Upon excitation, there was a shift of the orbital contribution from its initial position to the inorganic cluster, specifically at Zr atoms. This suggests the role of organic linker and inorganic cluster as electron donating and accepting units, respectively. However, the pattern of LUMO localization on the inorganic cluster was observed to be different from one adsorbent to another. In UiO-66, LUMO localized almost evenly on all six Zr atoms, while in the case of UiO-66-ATA, the LUMO distribution per Zr atom was unequal. For ML-UiO-66, as the substitution of ATA ligand into the framework was random, there were various patterns being observed. Specifically, in UiO-66-0.5ATA, the observation of two patterns was made; (1) evenly localized LUMO on all six Zr atoms similar to UiO-66 and (2) evenly localized LUMO on only four Zr atoms. Interestingly, in case of UiO-66-0.75ATA, only one pattern of orbital contribution existed where LUMO localized heavily on only four Zr atoms. 
This means the substitution of the functionalized ligand into the framework has an effect on the distribution of electron densities in the framework.

The results obtained from theoretical calculation suggests the charge transfer from organic ligand to inorganic cluster. This indicates a vital role of organic ligand in the determination of the charge character of the cluster. Hypotically, without an amino group, the electron density at inorganic clusters of UiO-66 possibly be lesser than those of the other three, which in turn generating lower degree of electrostatic repulsion between absorbent surface and anionic dyes and eventually higher capacity of removal. Meanwhile, in UiO-66-ATA, the opposite phenomenon occurred and thus resulted in its lower adsorbing capacity.

To support the proposed mechanism, adsorption of all four adsorbents toward different character of charged dyes were studied and the results are shown in Fig. 4 (b). It is evident that Ui0-66 shows higher adsorption capacity compared to UiO-66-ATA when tested with anionic dyes such as IC and methyl orange (MO). On contrary, a higher adsorption capacity is achieved by UiO-66-ATA in case of cationic dye such as methylene blue (MB). Interestingly, ML-UiO-66 shows higher adsorption capacity when compared to their parent MOFs in every dye system. This suggests that adsorption mechanism governs by several types of interactions which have to be in synergy. A mixed ligand approach can be one of the alternatives to engineer this interaction harmony. Noticeably, by employing mixed ligand approach, the adsorption capacity can be enhanced albeit with less impact than mixed metal approach. ${ }^{10}$ This could be hypothesized that the former approach only indirectly manipulates the cluster charge density, whereas the direct influence can be caused by the latter.

\section{Conclusion}

UiO-66 is an excellent choice of compound for dye adsorption, because of its unique properties. This study proves an introduction of ATA ligands into the material framework as a promising way to enhance and regulate its adsorption process. The introduced ATA ligands shows to have direct and simultaneous influences on several intrinsic parameters of the material at molecular level, which lead to changes in its macromolecular characters. In spite of intersting and potential of the mixed ligand approach, a common trend in its effect does not exist, making the mean still uncontrollable. As a result, it indicates a crucial neccessity of future works to be carried out in order to optimize the system

\section{Declarations}

\section{Conflict of interest}

The authors declare no conflict of interest.

\section{Acknowledgments}

This work was supported by the Research Funds from Walailak University (Grant number: WU-63211). The authors would like to thank University of Malaya for computational facilities and calculation programs

\section{References}

1. Thiry, M. C. Staying alive: making textiles sustainable(2011).

2. Desore, A. \& Narula, S. A. An overview on corporate response towards sustainability issues in textile industry. Environment, Development and Sustainability. 20, 1439-1459 https://doi.org/10.1007/s10668-017-9949-1 (2018).

3. Li, C., Xiong, Z., Zhang, J. \& Wu, C. The Strengthening Role of the Amino Group in Metal-Organic Framework MIL-53 (Al) for Methylene Blue and Malachite Green Dye Adsorption. Journal of Chemical \& Engineering Data. 60, 3414-3422 https://doi.org/10.1021/acs.jced.5b00692 (2015).

4. Huo, S. H. \& Yan, X. P. Metal-organic framework MIL-100(Fe) for the adsorption of malachite green from aqueous solution. Journal of Materials Chemistry. 22, 7449-7455 https://doi.org/10.1039/C2JM16513A (2012).

5. Chen, C., Zhang, M., Guan, Q. \& Li, W. Kinetic and thermodynamic studies on the adsorption of xylenol orange onto MIL-101(Cr). Chem. Eng. J. 183, 60-67 https://doi.org/10.1016/j.cej.2011.12.021 (2012).

6. Xu, Y. et al. Fabrication of hybrid magnetic HKUST-1 and its highly efficient adsorption performance for Congo red dye. RSC Advances. 5, 19199-19202 https://doi.org/10.1039/C5RA00384A (2015).

7. Nanthamathee, C. Effect of Co(II) dopant on the removal of Methylene Blue by a dense copper terephthalate. Journal of Environmental Sciences. 81, 68-79 https://doi.org/10.1016/j.jes.2019.02.002 (2019). 
8. Mohammadi, A. A. et al. Metal-organic framework Uio-66 for adsorption of methylene blue dye from aqueous solutions. International Journal of Environmental Science and Technology. 14, 1959-1968 https://doi.org/10.1007/s13762-017-1289-z (2017).

9. Molavi, H., Hakimian, A., Shojaei, A. \& Raeiszadeh, M. Selective dye adsorption by highly water stable metal-organic framework: Long term stability analysis in aqueous media. Appl. Surf. Sci. 445, 424-436 https://doi.org/10.1016/j.apsusc.2018.03.189 (2018).

10. Yang, J. M. et al. Adsorptive removal of organic dyes from aqueous solution by a Zr-based metal-organic framework: effects of Ce(iii) doping. Dalton Trans. 47, 3913-3920 https://doi.org/10.1039/C8DT00217G (2018).

11. Chen, Q. et al. Selective adsorption of cationic dyes by UiO-66-NH2. Appl. Surf. Sci. 327, 77-85 https://doi.org/10.1016/j.apsusc.2014.11.103 (2015).

12. Ge, J., Liu, L. \& Shen, Y. Facile synthesis of amine-functionalized UiO-66 by microwave method and application for methylene blue adsorption. Journal of Porous Materials. 24, 647-655 https://doi.org/10.1007/s10934-016-0301-1 (2017).

13. Qiu, J., Feng, Y., Zhang, X., Jia, M. \& Yao, J. Acid-promoted synthesis of UiO-66 for highly selective adsorption of anionic dyes: Adsorption performance and mechanisms. Journal of Colloid and Interface Science. 499, 151-158 https://doi.org/10.1016/j.jcis.2017.03.101 (2017).

14. Yang, J. M. A facile approach to fabricate an immobilized-phosphate zirconium-based metal-organic framework composite (UiO-66-P) and its activity in the adsorption and separation of organic dyes. Journal of Colloid and Interface Science. 505, 178-185 https://doi.org/10.1016/j.jcis.2017.05.040 (2017).

15. Embaby, M. S., Elwany, S. D., Setyaningsih, W. \& Saber, M. R. The adsorptive properties of UiO-66 towards organic dyes: A record adsorption capacity for the anionic dye Alizarin Red S. Chinese Journal of Chemical Engineering. 26, 731-739 https://doi.org/10.1016/j.cjche.2017.07.014 (2018).

16. Han, Y. et al. In situ synthesis of titanium doped hybrid metal-organic framework UiO-66 with enhanced adsorption capacity for organic dyes. Inorg. Chem. Front. 4, 1870-1880 https://doi.org/10.1039/C7QI00437K (2017).

17. Zhang, K. D. et al. Adsorption Behavior of High Stable Zr-Based MOFs for the Removal of Acid Organic Dye from Water. Materials. 10, 205 https://doi.org/10.3390/ma10020205 (2017).

18. Masoomi, M. Y., Morsali, A., Dhakshinamoorthy, A. \& Garcia, H. Mixed-Metal MOFs: Unique Opportunities in Metal-Organic Framework (MOF) Functionality and Design. Angew. Chem. Int. Ed. 58, 15188-15205 https://doi.org/10.1002/anie.201902229 (2019).

19. Cavka, J. H. et al. A New Zirconium Inorganic Building Brick Forming Metal Organic Frameworks with Exceptional Stability. Journal of the American Chemical Society. 130, 13850-13851 https://doi.org/10.1021/ja8057953 (2008).

20. Langmuir, I. \& THE CONSTITUTION AND FUNDAMENTAL PROPERTIES OF SOLIDS AND LIQUIDS. PART I. SOLIDS. Journal of the American Chemical Society. 38, 2221-2295 https://doi.org/10.1021/ja02268a002 (1916).

21. Freundlich, H. M. F. Z. Over the adsorption in solution. Phys. Chem. 57, 385-471 (1906).

22. Frisch, M. J. et al. J. W., J. B. Foresman, and D. J. Fox, Gaussian, Inc., Wallingford CT,. Gaussian 09. Gaussian, Inc.(2016).

23. Dennington, R. \& Millam, T. K. J. Gauss View, Version 5.Semichem Inc.Shawnee Mission, (2009).

24. Ferreira, R. B., Scheetz, P. M. \& Formiga, A. L. B. Synthesis of amine-tagged metal-organic frameworks isostructural to MIL-101(Cr). RSC Advances. 3, 10181-10184 https://doi.org/10.1039/C3RA23443F (2013).

25. Ezugwu, C. I. et al. Efficient transformative HCHO capture by defective NH2-UiO-66(Zr) at room temperature. Environmental Science: Nano. 6, 2931-2936 https://doi.org/10.1039/C9EN00871C (2019).

26. Valenzano, L. et al. Disclosing the Complex Structure of UiO-66 Metal Organic Framework: A Synergic Combination of Experiment and Theory. Chemistry of Materials. 23, 1700-1718 https://doi.org/10.1021/cm1022882 (2011).

27. Zhang, N. et al. Extending the Use of Highly Porous and Functionalized MOFs to Th(IV) Capture. ACS Applied Materials \& Interfaces. 9, 25216-25224 https://doi.org/10.1021/acsami.7b04192 (2017).

28. Wu, H. et al. Unusual and Highly Tunable Missing-Linker Defects in Zirconium Metal-Organic Framework UiO-66 and Their Important Effects on Gas Adsorption. Journal of the American Chemical Society. 135, 10525-10532 https://doi.org/10.1021/ja404514r (2013).

29. Luu, C. L., Nguyen, T. T. V., Nguyen, T. \& Hoang, T. C. Synthesis, characterization and adsorption ability of UiO-66-NH 2. Advances in Natural Sciences: Nanoscience and Nanotechnology. 6, 025004 https://doi.org/10.1088/2043-6262/6/2/025004 (2015).

30. Chavan, S. M. et al. Synthesis and Characterization of Amine-Functionalized Mixed-Ligand Metal-Organic Frameworks of UiO-66 Topology. Inorg. Chem. 53, 9509-9515 https://doi.org/10.1021/ic500607a (2014).

31. Jiao, Y. et al. Heat-Treatment of Defective UiO-66 from Modulated Synthesis: Adsorption and Stability Studies. The Journal of Physical Chemistry C. 121, 23471-23479 https://doi.org/10.1021/acs.jpcc.7b07772 (2017).

32. Senthil Kumar, P. et al. Adsorption of dye from aqueous solution by cashew nut shell: Studies on equilibrium isotherm, kinetics and thermodynamics of interactions. Desalination. 261, 52-60 https://doi.org/10.1016/j.desal.2010.05.032 (2010). 
33. Mittal, A., Mittal, J. \& Kurup, L. Batch and bulk removal of hazardous dye, indigo carmine from wastewater through adsorption. Journal of Hazardous Materials. 137, 591-602 https://doi.org/10.1016/j.jhazmat.2006.02.047 (2006).

34. Zhang, J., Zhou, Q. \& Ou, L. Removal of indigo carmine from aqueous solution by microwave-treated activated carbon from peanut shell. Desalination and Water Treatment. 57, 718-727 https://doi.org/10.1080/19443994.2014.967729 (2016).

35. Kumar, K. V. et al. Characterization of the adsorption site energies and heterogeneous surfaces of porous materials. Journal of Materials Chemistry A. 7, 10104-10137 https://doi.org/10.1039/C9TA00287A (2019).

36. Chen, F., Zhou, C., Li, G. \& Peng, F. -f. Thermodynamics and kinetics of glyphosate adsorption on resin D301. Arabian Journal of Chemistry. 9, S1665-S1669 https://doi.org/10.1016/j.arabjc.2012.04.014 (2016).

37. Banerjee, S., Sharma, G. C., Chattopadhyaya, M. C. \& Sharma, Y. C. Kinetic and equilibrium modeling for the adsorptive removal of methylene blue from aqueous solutions on of activated fly ash (AFSH). Journal of Environmental Chemical Engineering. 2, 1870-1880 https://doi.org/10.1016/j.jece.2014.06.020 (2014).

38. Zybaylo, O. et al. A novel method to measure diffusion coefficients in porous metal-organic frameworks. Physical Chemistry Chemical Physics. 12, 8093-8098 https://doi.org/10.1039/B927601G (2010).

39. Agrawal, M., Boulfelfel, S. E., Sava Gallis, D. F., Greathouse, J. A. \& Sholl, D. S. Determining Diffusion Coefficients of Chemical Warfare Agents in Metal-Organic Frameworks. The Journal of Physical Chemistry Letters. 10, 7823-7830 https://doi.org/10.1021/acs.jpclett.9b03119 (2019).

40. Al-Ghouti, M. A. \& Al-Absi, R. S. Mechanistic understanding of the adsorption and thermodynamic aspects of cationic methylene blue dye onto cellulosic olive stones biomass from wastewater. Sci. Rep. 10, 15928 https://doi.org/10.1038/s41598-020-72996-3 (2020).

41. Hu, J. et al. Enhanced adsorptive removal of hazardous anionic dye "congo red" by a Ni/Cu mixed-component metal-organic porous material. RSC Advances. 4, 35124-35130 https://doi.org/10.1039/C4RA05772D (2014).

42. Li, X. et al. Thermodynamics and Kinetics of p-Aminophenol Adsorption on Poly(aryl ether ketone) Containing Pendant Carboxyl Groups. Journal of Chemical \& Engineering Data. 56, 4274-4277 https://doi.org/10.1021/je2009297 (2011).

43. Doménech, A., Doménech-Carbó, M. T., de Vázquez, A. \& Pascual, M. L. Indigo/Dehydroindigo/Palygorskite Complex in Maya Blue: An Electrochemical Approach. The Journal of Physical Chemistry C. 111, 4585-4595 https://doi.org/10.1021/jp067369g (2007).

44. Caratelli, C. et al. Nature of active sites on UiO-66 and beneficial influence of water in the catalysis of Fischer esterification. Journal of Catalysis. 352, 401-414 https://doi.org/10.1016/j.jcat.2017.06.014 (2017).

45. Hendrickx, K. et al. Understanding Intrinsic Light Absorption Properties of UiO-66 Frameworks: A Combined Theoretical and Experimental Study. Inorg. Chem. 54, 10701-10710 https://doi.org/10.1021/acs.inorgchem.5b01593 (2015).

\section{Figures}



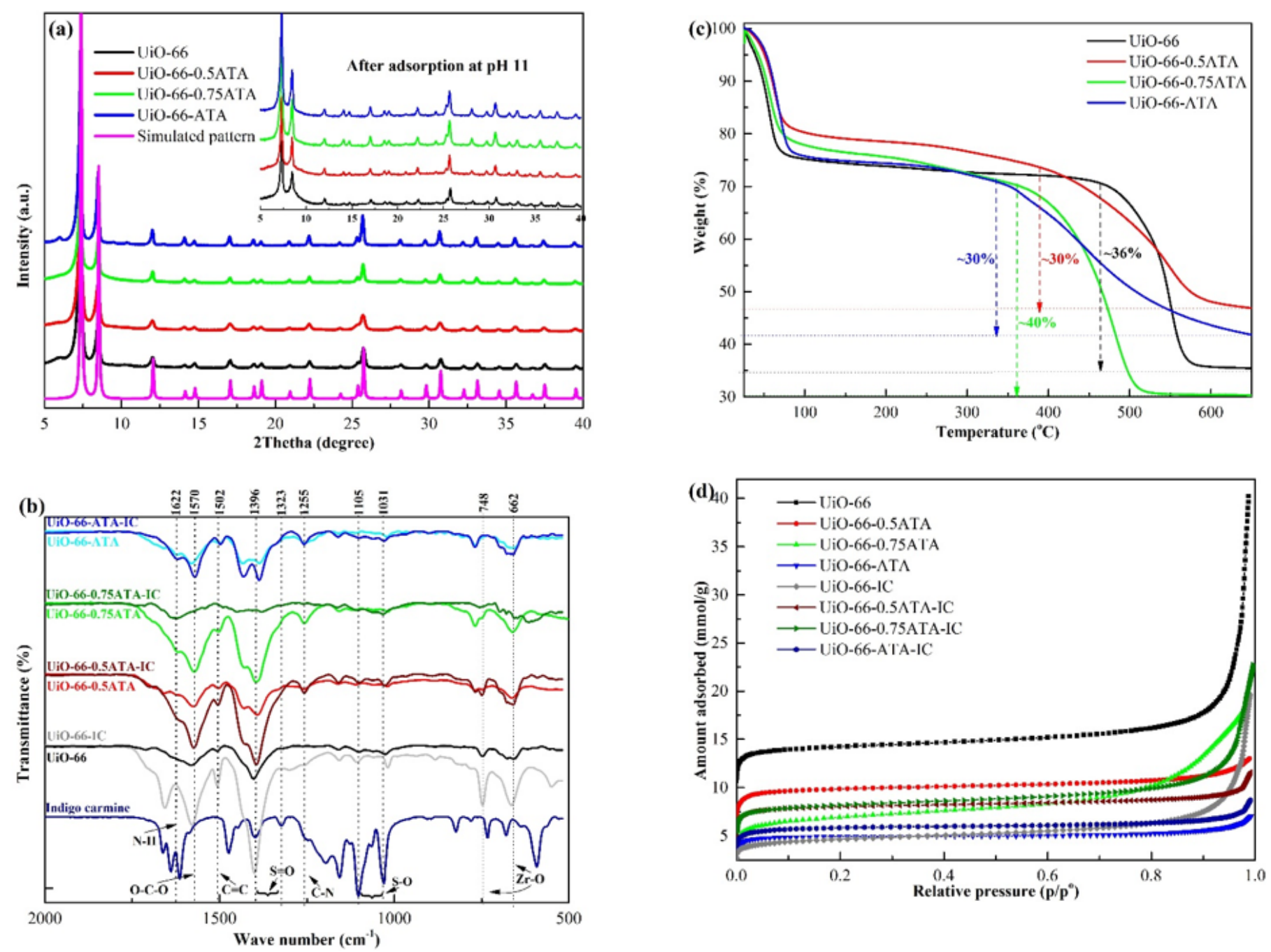

\section{Figure 1}

Characterization of all adsorbents (a) powder X-ray diffraction patterns (PXRD) of as-made UiO-66, UiO-66-0.5ATA, UiO-66-0.75ATA and UiO-66ATA where the inset shows PXRD patterns of all materials after adsorption at $\mathrm{pH}=11 \mathrm{for} 24 \mathrm{hr}$. (b) IR spectra of the emptied adsorbents, IC loaded adsorbents and IC dye (c) TGA plots of the calcined UiO-66, UiO-66-0.5ATA, Ui0-66-0.75ATA and UiO-66-ATA (d) BET surface area of UiO-66, UiO-66-0.5ATA, UiO-66-0.75ATA and UiO-66-ATA before and after IC adsorption. 

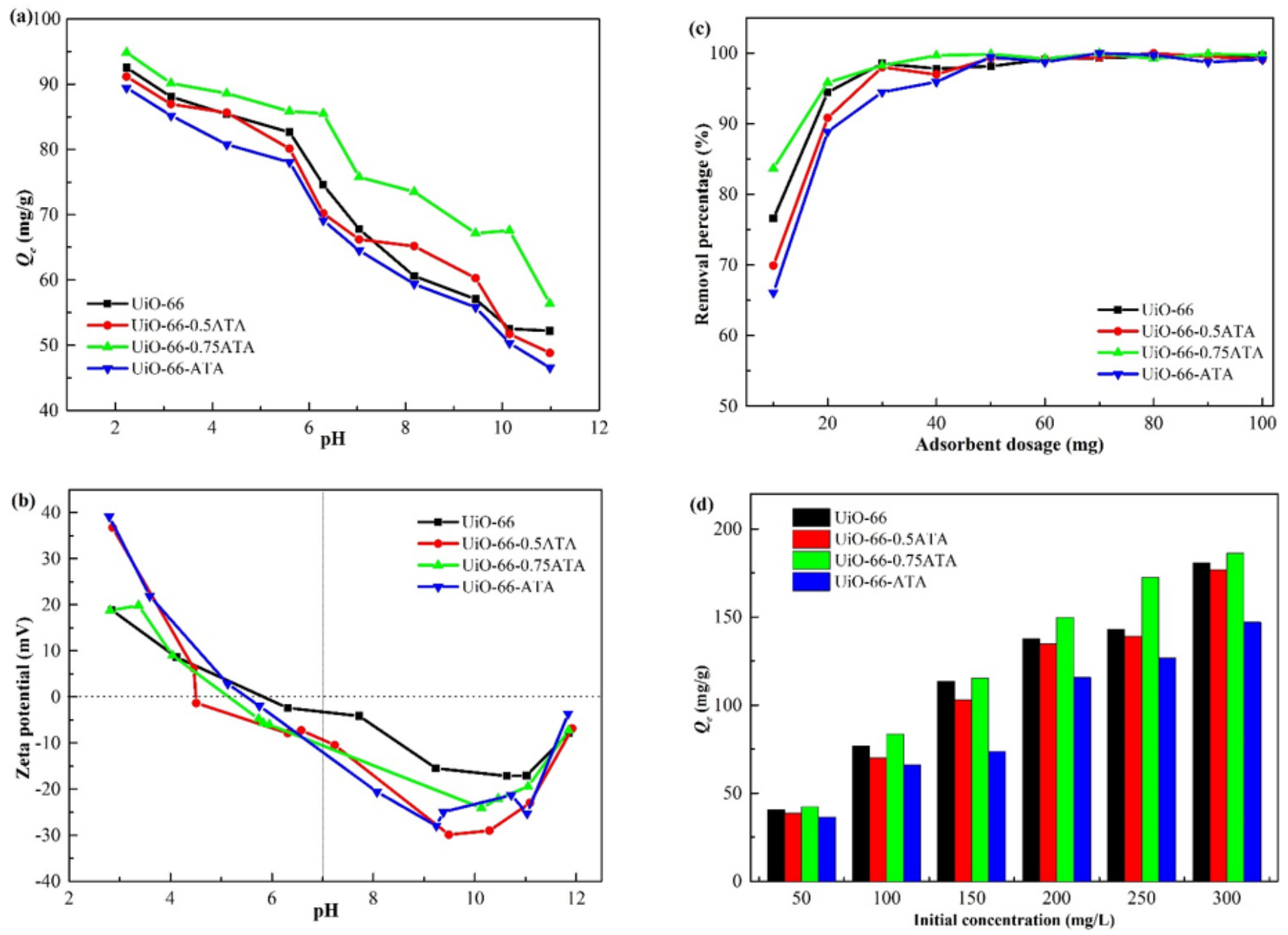

Figure 2

(a) Effect of $\mathrm{pH}$ on the adsorption of IC by UiO-66, UiO-66-0.5ATA, UiO-66-0.75ATA and UiO-66-ATA (b) Zeta potential measurement for UiO-66, UiO-66-0.5ATA, UiO-66-0.75ATA and UiO-66-ATA as a function of $\mathrm{pH}$ (c) Effect of adsorption dosage on the removal percentage of IC by UiO-66, UiO-66-0.5ATA, UiO-66-0.75ATA and UiO-66-ATA (d) effect of IC initial concentration on the adsorption of IC by UiO-66, UiO-66-0.5ATA, UiO-660.75ATA and UiO-66-ATA 

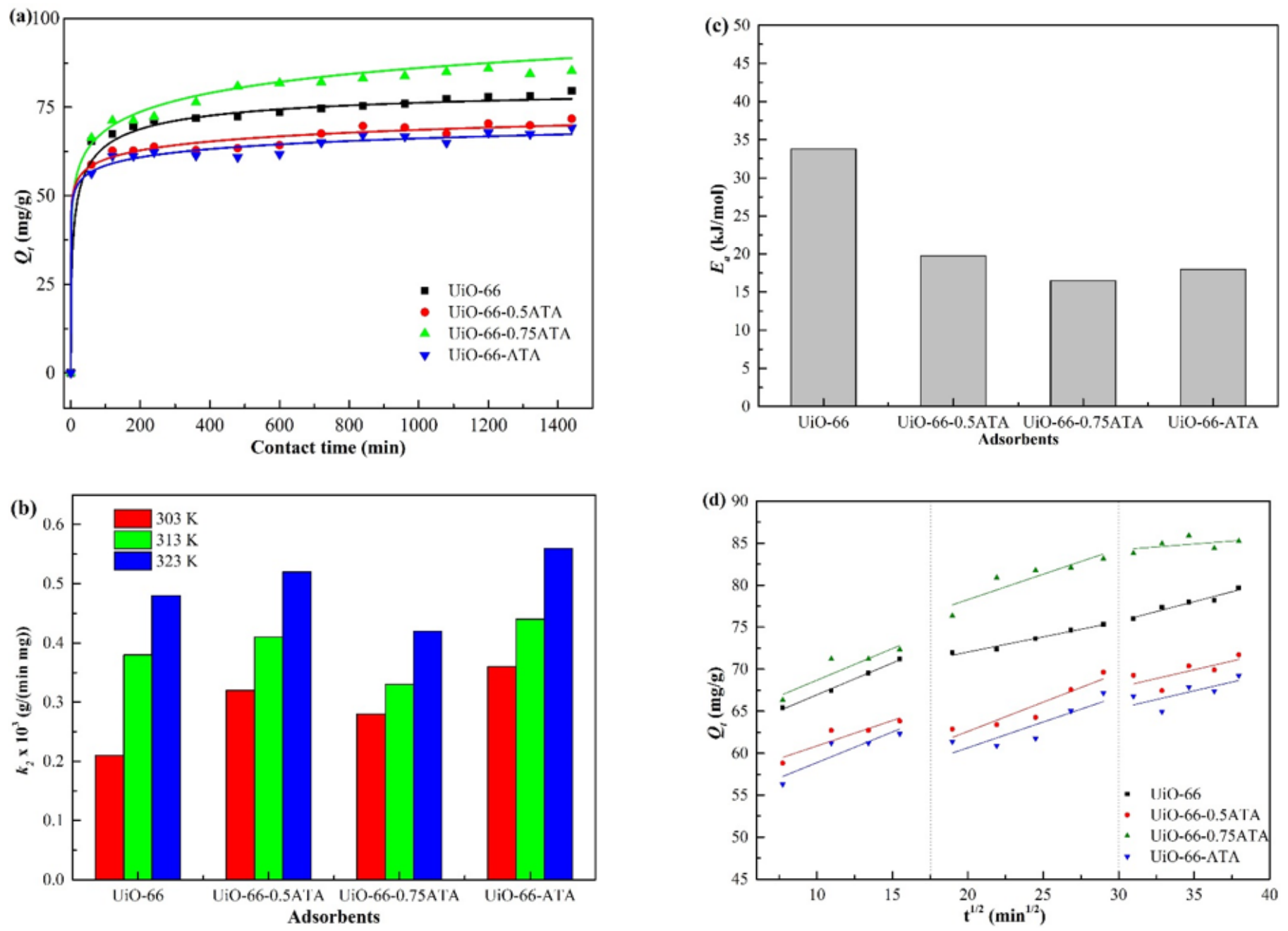

Figure 3

(a) Effect of contact time on adsorption of IC by UiO-66, UiO-66-0.5ATA, UiO-66-0.75ATA and UiO-66-ATA at 303 K. (b) Variation of rate constant (k2) with temperature obtained from pseudo-second order model (c) Apparent activation energy (Ea) of the IC adsorption. (d) The plot of intraparticle diffusion model for IC adsorption by Ui0-66, UiO-66-0.5ATA, UiO-66-0.75ATA and UiO-66-ATA at 303 K. 
(a)
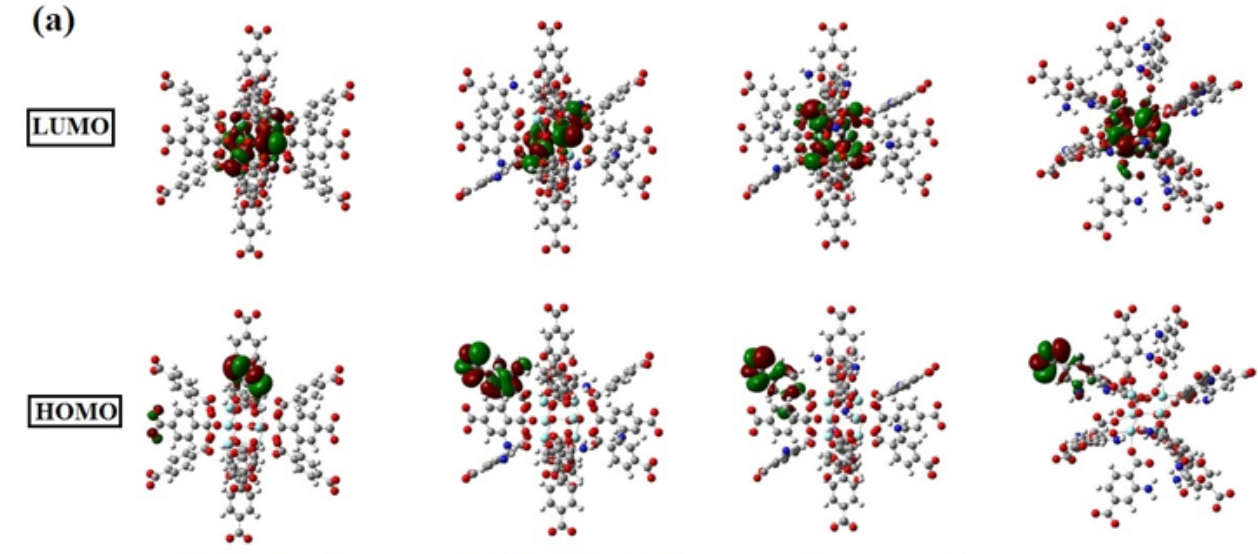

$\left[\mathrm{Zr}_{6} \mathrm{O}_{4}(\mathrm{OH}) 4(\mathrm{BDC})_{22}\right]^{122}$

$\left[\mathrm{Zr}_{6} \mathrm{O}_{4}(\mathrm{OH})_{4}(\mathrm{BDC})(\mathrm{ATA})_{6}\right]^{12}$

$\left[\mathrm{Zr}_{6} \mathrm{O}+(\mathrm{OH}) 4(\mathrm{BDC})_{3}(\mathrm{ATA})\right]^{12}$

$\left[\mathrm{Zr}_{6} \mathrm{O}_{4}(\mathrm{OH})_{4}(\mathrm{ATA})_{12}\right]^{12}$

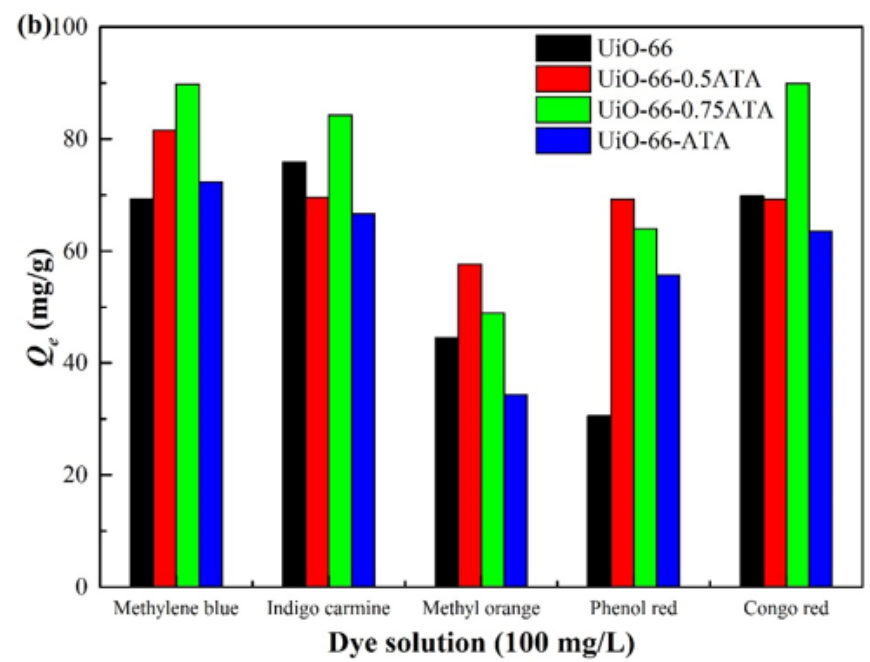

Figure 4

(a) The selected excited state molecular orbitals (LUMO) of [Zr6O4(OH)4(OOC-C6H4-COO)12]12-, [Zr6O4(OH)4(OOC-C6H4-COO)6(OOCC6H6N-C0O)6]12-, [Zr6O4(OH)4(OOC-C6H4-COO)3(0OC-C6H6N-COO)9]12- and [Zr6O4(OH)4(OOC-C6H6N-COO)12]12- calculating at PBE1PBE/LanL2DZ level of accuracy (b) Adsorption capacity of UiO-66, UiO-66-0.5ATA, UiO-66-0.75ATA and UiO-66-ATA at different types of dyes solution (dye concentration $=100 \mathrm{ppm}, \mathrm{pH}=6.5$, contact time $=24$ hours, adsorbent dosage $=10.0000 \mathrm{mg}$ in $10.00 \mathrm{~mL}$ dye solution)

\section{Supplementary Files}

This is a list of supplementary files associated with this preprint. Click to download.

- SupportinginformationCN.docx 